\title{
Are Mannan-binding Lectine Serin Protease-2 and Alpha-1-microglobulin and Bukinin Precursor the Potential Biomarkers of Manic Episode? A Study via Urinary Proetomic Analysis
}

\author{
Cem Cerit', Mehmet Sarıhan², Ömer Nart', Murat Kasap², Hilmi Yaşar', Gürler Akpınar² \\ ${ }^{1}$ Department of Psychiatry, ${ }^{2}$ Department of Medical Biology, School of Medicine, Kocaeli University, Kocaeli, ${ }^{3}$ Clinic of Psychiatry, Bursa State \\ Hospital, Bursa, Turkey
}

\begin{abstract}
Objective: Investigating the molecular basis of bipolar disorder (BD) is crucial in terms of developing effective treatment strategies as well as objective laboratory-based diagnostic tools for the disease.

Methods: We examined the urine samples of BD patients both in manic episode and after remission and compared their urinary protein profiles with the controls. Twelve patients and twelve controls (C group) included to the study. Urinary samples of patients were first collected during manic episode ( $M$ group) and then after remission ( $R$ group). Two-dimensional gel electrophoresis (2-DE) coupled to MALDI-TOF/TOF massspectrometry approach and Western blot analysis were used.

Results: Alpha-1-microglobulin and bukinin precursor (AMBP), Mannan-binding lectine serin protease-2 (MASP-2), and Ig gamma-1-chain displayed significant increases in their abundance in the urine protein pool of $\mathrm{M}$ group in comparison to the $\mathrm{C}$ and $\mathrm{R}$ groups. Alpha-1B glycoprotein and prostaglandin-H2 D-isomerase (PGD2) levels were significantly higher in the urine protein pool of the $M$ and $R$ groups in comparison to the $C$ group. Annexin A1 was downregulated significantly in the urine protein pool of the $M$ group in comparison to the $C$ group.

Conclusion: Intensities of MASP-2 and AMBP proteins discriminated manic episode from remission period and healthy controls indicating that these proteins may be candidate biomarkers for manic episode. The decrease in Annexin A1 and increase in Ig gamma-1 chain levels appeared to be associated with "Manic Episode" while the increase in PGD2 and alpha-1B glycoprotein levels appeared to be associated with "Bipolar Disorder".
\end{abstract}

KEY WORDS: Bipolar disorder; Manic state; Proteomics; Biomarkers; Mannan-binding lectine serin protease-2; Alpha-1microglobulin and bukinin precursor.

\section{INTRODUCTION}

Bipolar disorder (BD) is a chronic, severe and debilitating mental illness characterized by depressive and manic episodes and euthymic periods. It is among the world's ten most disabling conditions, taking away years of healthy functioning from individuals who have the illness [1]. Currently, the diagnosis of BD is subjective and mostly relies on clinical interviews with the patients, interpretation of lifetime symptoms and/or the use of stand-

Received: June 16, 2020 / Revised: August 15, 2020

Accepted: August 28, 2020

Address for correspondence: Cem Cerit

Department of Psychiatry, School of Medicine, Kocaeli

University, 41380, Umuttepe, Kocaeli, Turkey

E-mail: cemcerit@yahoo.com

ORCID: https://orcid.org/0000-0002-0189-7003 ardized questionnaires. Despite the major ongoing efforts with promising future perspectives, no reliable biomarker of $\mathrm{BD}$ has found a place in the clinics [2]. Therefore, a proper biomarker or a biomarker panel that would allow reliable diagnosis of $\mathrm{BD}$ is needed. So far, candidate peripheral protein markers for $\mathrm{BD}$ have been proposed [3]. Among those biomarker candidates, some displayed changes in their abundance in the serum samples collected from the BD patients compared to the controls [4-6]. Similarly, some other protein-based putative biomarkers appear to change their level of presence in CSF in BD patients in comparison to the controls [7]. When post-mortem brain tissues of BD patients were examined and compared with the controls, a list of candidate protein-based biomarkers for BD was foreseen [8]. Yet, due

(c) This is an Open-Access article distributed under the terms of the Creative Commons Attribution Non-Commercial License (http://creativecommons.org/licenses/by-nc/4.0) which permits unrestricted non-commercial use, distribution, and reproduction in any medium, provided the original work is properly cited. 
to the unlikeliness of sampling brain tissues for diagnostic purposes, those proteins were not received attention as possible biomarker canidates and were rather used for elucidation of underlying molecular mechanisms of $\mathrm{BD}$. In parallel to the search for a protein-based biomarkers other types of biomarker molecules including hormonebased, peptide-based and microRNA-based ones were searched [9-11]. Those studies also stayed fruitless.

What is noticable of the BD biomarker studies is the lack of interest in urine as the biological biomarker source. The lack of interest in urine as a source of biomarker in $\mathrm{BD}$ is reasonable since urine does not have a way to directly contact with the brain within the body and is less likely to possess brain-derived biomarker molecules. However, this is a serious misconception since several urine-dwelled biomarker molecules for neurological diseases were proposed [12].

In this study, we examined the urine samples of $\mathrm{BD}$ patients both in manic episode and after remission and compared their urinary protein profiles with the healthy controls. The comparisions were made using two-dimentional gel-based proteomics approach coupled to the MALDITOF/TOF mass spectrometry analysis.

\section{METHODS}

\section{Participants and Procedure}

The study was conducted in Turkey at Kocaeli University Research and Education Hospital, Department of Psychiatry during the period of February 2018 to June 2018. Wet laboratory experiments were carried out at Kocaeli University DEKART Proteomics laboratory. Twelve patients who were admitted to the inpatient unit of Psychiatry Clinic with a diagnosis of acute mania were the subjects of this study. The exclusion criteria for the subjects included the presence of a chronic physical disorder such as diabetes mellitus, congestive heart failure, kidney failure, neurological disorders, mental disorders other than $\mathrm{BD}$, alcohol or substance use disorders, and presence of an infectious disease. In order to exclude infectious states, participants were asked for clinical symptoms and also complate blood count and complate urine analysis were performed. The Diagnostic and Statistical Manual of Mental Disorders, Fifth Edition was used for the diagnosis of BD, manic episode. Study investigators did not participate the medication of the patients and patients remained in con- tact with the investigator with planned visits. Clinical assessments were performed in every 2 weeks in inpatient unit or after discharge from hospital. The urine samples of patients were first collected a day after hospitalization when the patient was in manic episode (M group). Secondly urine samples were collected when these patients were defined as remitted (R group) in planned visits. Remission was defined as a Young Mania Rating Scale score of 7 or less and a total 21-item Hamilton Depression Scale score of 7 or less [13].

Twelve age and sex-matched healty individuals were included in the study as controls ( $C$ group). The voluntary control subjects were the employees of the hospital. Exclusion criteria used for the controls were; having a current or history of chronic physical, neurological, mental disorder and alcohol or substance use disorder in themselves or in their 1st-degree relatives.

\section{Sample Collection and Pools}

The urine samples were collected into sterile urine containers. To clarify and remove any insoluble material, $5 \mathrm{ml}$ of each urine sample was decanted into sterile $15 \mathrm{ml}$ falcon tubes, kept on ice for 15 minutes and centrifuged at $430 \mathrm{~g} \times \mathrm{g}$ at $4^{\circ} \mathrm{C}$ for 10 minutes. The cleared urine samples were then carefully removed and frozen at $-80^{\circ} \mathrm{C}$ in $2 \mathrm{ml}$ aliquots.

\section{Preparation of Urine Pools}

Urine pools were prepared by combining equal volumes of urine from each sample [14]. The pools were concentrated and filtered with a $5 \mathrm{kDa}$ polyethersulfone membrane (Millipore PBCC02510; MilliporeSigma, Burlington, MA, USA) using a Stirred Cell system (Amicon; MilliporeSigma) to $0.5 \mathrm{ml}$ final volume. Concentrated urine pools were then transferred into $1.5 \mathrm{ml}$ Eppendorf tubes (Corning-Axygen, Tewksbury, MA, USA). Bradford assay (Bio-Rad, Hercules, CA, USA) with Bovine Serum Albumin (BSA) as the standard was used to measure protein concentrations.

\section{Assessment of Protein Quality and Quantity in Urine Pools}

Twenty $\mu \mathrm{g}$ protein from each concentrated urine pool was loaded onto the wells of a $12 \%$ SDS-polyacrylamide gel to assess protein quality and quantity. The gel was run at $180 \mathrm{~V}$ for 45 minutes and the proteins were fixed and 
then stained with Colloidal Coomassie blue (Bio-Rad) and imaged with VersaDoc MP 4000 (BioRad).

\section{Two-dimensional Gel Electrophoresis (2-DE)}

Two hundred $\mu \mathrm{g}$ of protein from each protein pool was diluted with 2-DE rehydration buffer and loaded onto immobilized $\mathrm{pH}$ gradient strips $(11 \mathrm{~cm}, \mathrm{pH} 3-10 \mathrm{NL}$ [nonlinear]) by passive rehydration. Isoelectronic focusing (IEF) was achieved under the following conditions: 20 minutes at $250 \mathrm{~V}$ with rapid ramp, 2.5 hours at $8,000 \mathrm{~V}$ with slow ramp and 2.5 hours for $8,000 \mathrm{~V}$ with a rapid ramp until a total of $20.000 \mathrm{~V} / \mathrm{h}$ was reached at $20^{\circ} \mathrm{C}$ using Protean IEF system (Bio-Rad). After isoelectric focusing, strips were then washed with buffer I (6 M Urea, 375 $\mathrm{mM}$ Tris- $\mathrm{HCl} \mathrm{pH}$ 8.8, 2\% SDS, 20\% glycerol, 2\% [w/v] 1,4-Dithiothreitol [DTT]) for 30 minutes and then with buffer II (6 M Urea, 375 mM Tris- $\mathrm{HCl}$ pH 8.8, 2\% SDS, $20 \%$ glycerol, $2.5 \%$ iodoacetamide [w/v]) for 30 minutes at room temperature. The strips were then placed onto $12 \%$ SDS-polyacrylamide gels and were subjected to a second dimension separation in a Dodeca gel running system (Bio-Rad). Two gels were run for each sample and were fixed and stained with Colloidal Coomassie blue and imaged with VersaDoc MP 4000.

\section{Image Analysis and Spot Cutting}

PD Quest Advance 2D-analysis software (Bio-Rad) was used for comparative analysis of protein spots on 2-DE gels. The quantity of each spot was normalized using the total valid spot intensity. Total spot numbers and volumes within the normalized area were determined by the automated analyses. A manual editing tool was used to inspect the protein spots detected by the software. The spots were cut using automated spot cutting tool, ExQuest spot cutter (Bio-Rad), and disposed into a 96-well plate for protein identification.

\section{Protein Identification by Mass Spectrometry}

In-gel tryptic digestion of the proteins was performed using an in-gel digestion kit (Thermo Fisher Scientific, Waltham, MA, USA) as described in Kanli et al. [15]. Protein identification experiments were with ABSCIEX 5800 MALDI-TOF/TOF system (AB Sciex, Framingham, MA, USA). Before deposition onto a MALDI plate, all samples were desalted, and concentrated with a $10 \mu \mathrm{I}$ ZipTip (C18) following the recommended protocol (Merck KGaA,
Darmstadt, Germany). The TOF spectra were recorded in the positive ion reflector mode with a mass range from 400 to 2,000 Da. Each spectrum was the cumulative average of 200 laser shots. The spectra were calibrated with the trypsin autodigestion ion peaks (m/z 842.510 and 2211.1046) as internal standards. Ten of the strongest peaks of the TOF spectra per sample were chosen for tandem mass spectrometry (MS/MS) analysis. All of the peptide mass fingerprints were searched in the MASCOT version 2.5 (Matrix Science, Boston, MA, USA) using a streamline software, Protein Pilot (AB SCIEX, Framingham, MA, USA). $A$ database was created using the entries in NCBI-NR (https://www.ncbi.nlm.nih.gov/refseq/about/nonredundantproteins/) and implemented into the MASCOT search engine. The search criteria included: enzyme of trypsin; at least five independent peptides matched; at most one missed cleavage site; MS tolerance set to $50 \mathrm{ppm}$ and MS/MS tolerance set to $0.4 \mathrm{Da}$; fixed modification being internal carbamidomethyl (Cys) and variable modification being oxidation (Met); peptide charge of $1+$ and being monoisotopic. Only significant hits, as defined by the MASCOT probability analysis $(p<0.05)$, were accepted. Protein score is $-10 \times \log (P)$ where is the $P$ is the probability that the observed match is a random event. Protein scores were derived from ion scores as a non-probabilistic basis for ranking protein hits. Protein scores, which had a value of $p<0.05$ is considered significant hits.

\section{Western Blot (WB) Analysis}

Normalized protein samples were separated on SDSPAGE gels and transferred onto membranes for blotting. Ponceua $\mathrm{S}$ stain was used to assess equal protein transfer. The membranes were blocked in Tris-buffered saline with $0.1 \%$ Tween 20 Detergent (TBS-T) solution containing 5\% non-fat dried milk for 1 hour at room temperature and incubated with the primary antibodies overnight at $4^{\circ} \mathrm{C}$. Secondary antibody incubations were also performed at room temperature for 1 hour. The antibodies used were monoclonal anti-alpha 1-Microglobulin Antibody (MAB7724; Novus Biologicals, Centennial, CO, USA) and monoclonal anti-MASP-2 Antibody (NBP1-58986; Novus Biologicals). The protein bands were visualized with ECL detection system (Bio-Rad) on X-ray films. The quantifications of the bands were performed using Quantity One 1D image analysis software (Bio-Rad). Western blotting experiments were repeated at least three times. 


\section{Statistical Analysis}

Data were analysed with IBM SPSS software version 20.0 (IBMCo., Armonk, NY, USA). The Kolmogorov-Smirnov test and Skewness and Kurtosis values were used to assess the normality of data distributions. The data are expressed as mean \pm standard deviation or median (range) when necessary. Paired samples $t$ test (two tailed) was used to compare the continuous variables between group $\mathrm{M}$ and group R. Independent samples $t$ test (two tailed) was used to compare the continuous variables of group $C$ to group $M$ and R. Mann - Whitney $U$ test was used to compare the continuous variables between groups when necessary. Chi square test was used to compare the categorical variables between groups. A value of $p<0.05$ was considered statistically significant.

\section{Ethics Statements}

The local ethics committee of Kocaeli University approved this study under the approval number of KOUKAEK 2016/146. Informed consents were obtained from each participant and 1st-degree relative of the patient with manic episode.

Table 1. Clinical variables of participants

\begin{tabular}{lccc}
\hline \multicolumn{1}{c}{ Variable } & $\begin{array}{c}\text { Bipolar disorder } \\
(\mathrm{n}=12)\end{array}$ & $\begin{array}{c}\text { Control } \\
(\mathrm{n}=12)\end{array}$ & $p$ value \\
\hline $\begin{array}{l}\text { Age }(\mathrm{yr}) \\
\text { Sex }(\mathrm{n})\end{array}$ & $36.36 \pm 11.76$ & $33.83 \pm 7.99$ & 0.550 \\
$\quad$ Female & 6 & 6 & $>0.99$ \\
$\quad \begin{array}{l}\text { Male } \\
\text { Number of depressive }\end{array}$ & $1.5(3)$ & 6 & \\
$\quad$ episodes & $2(6)$ & & \\
$\begin{array}{l}\text { Number of manic } \\
\text { episodes }\end{array}$ & & & \\
$\begin{array}{l}\text { Number of } \\
\text { hospitalizations }\end{array}$ & $3.80 \pm 2.66$ & & \\
$\begin{array}{l}\text { Duration of the } \\
\text { disorder (mo) }\end{array}$ & $107.00 \pm 82.05$ & & \\
Time to remission (wk) & $5(4)$ & & \\
YMRS- (M group) & $27.50 \pm 5.26$ & \\
YMRS- (R group) & $2.66 \pm 2.14$ & \\
HAM-D & $2.75 \pm 1.95$ & & \\
\hline
\end{tabular}

Data are presented as mean \pm standard deviation or median (range). YMRS- (M group),Young Mania Rating Scale score of patients in manic episode YMRS- (R group), Young Mania Rating Scale score of patients in remission phase HAM-D, Hamilton Depression Scale score in remission phase.

\section{RESULTS}

The clinical variables of the BD patients and the controls were presented in Table 1. No statistically significant difference was found between the groups in terms of age and sex. The mean duration of the disorder was nearly 9 years and the mean time to remission was 5 weeks after hospitalization. Drug treatments of patients were presented in Table 2. Patients were mostly using antipsychotics and mood stabilizers.

\section{Preparation of Urine Protein Pools to 2-DE}

Accurate determination of protein concentrations among different biological samples is crucial to reliably compare protein profiles. In general, a house keeping protein e.g.,

Table 2. Drug treatments of patients

\begin{tabular}{|c|c|c|}
\hline Patient & Treatment in acute mania & Treatment in remission \\
\hline 1 & $\begin{array}{l}\text { Zuclopenthixol acetate } 50 \\
\mathrm{mg} / \mathrm{ml} \\
\text { Olanzapine } 20 \mathrm{mg} / \text { day }\end{array}$ & $\begin{array}{l}\text { Lithium } 600 \text { mg/day } \\
\text { Olanzapine } 2.5 \text { mg/day }\end{array}$ \\
\hline 2 & $\begin{array}{l}\text { Olanzapine } 20 \text { mg/day } \\
\text { Valproate 1,000 mg/day } \\
\text { Clonazepam } 4 \text { mg/day }\end{array}$ & $\begin{array}{l}\text { Valproate } 1,000 \mathrm{mg} / \text { day } \\
\text { Quetiapine } 100 \mathrm{mg} / \text { day }\end{array}$ \\
\hline 3 & $\begin{array}{l}\text { Lithium } 600 \text { mg/day } \\
\text { Quetiapine } 400 \text { mg/day }\end{array}$ & Lithium 600 mg/day \\
\hline 4 & $\begin{array}{l}\text { Quetiapine } 400 \text { mg/day } \\
\text { Risperidone } 37.5 \text { mg/2 } \\
\text { weeks }\end{array}$ & $\begin{array}{l}\text { Lithium } 900 \text { mg/day } \\
\text { Quetiapine } 600 \text { mg/day }\end{array}$ \\
\hline 5 & $\begin{array}{l}\text { Haloperidol } 20 \text { mg/day } \\
\text { Valproate 1,000 mg/day } \\
\text { Biperiden hydrochloride } 4 \\
\text { mg/day }\end{array}$ & Valproate 1,000 mg/day \\
\hline 6 & $\begin{array}{l}\text { Aripiprazole } 30 \text { mg/day } \\
\text { Clonazepam } 4 \text { mg/day }\end{array}$ & $\begin{array}{l}\text { Aripiprazole } 15 \text { mg/day } \\
\text { Clonazepam } 1 \text { mg/day }\end{array}$ \\
\hline 7 & $\begin{array}{l}\text { Valproate 1,500 mg/day } \\
\text { Olanzapine } 10 \mathrm{mg} / \text { day } \\
\text { Clonazepam } 4 \text { mg/day }\end{array}$ & $\begin{array}{l}\text { Valproate } 1,000 \mathrm{mg} / \text { day } \\
\text { Olanzapine } 7.5 \mathrm{mg} / \text { day }\end{array}$ \\
\hline 8 & $\begin{array}{l}\text { Olanzapine } 15 \text { mg/day } \\
\text { Clonazepam } 2 \text { mg/day }\end{array}$ & Olanzapin 10 mg/day \\
\hline 9 & $\begin{array}{l}\text { Risperidone } 50 \mathrm{mg} / 2 \text { weeks } \\
\text { Quetiapine } 800 \mathrm{mg} / \text { day }\end{array}$ & $\begin{array}{l}\text { Risperidone } 50 \mathrm{mg} / 2 \text { weeks } \\
\text { Quetiapine } 400 \mathrm{mg} / \text { day }\end{array}$ \\
\hline 10 & $\begin{array}{l}\text { Valproate 1,000 mg/day } \\
\text { Olanzapine } 20 \text { mg/day }\end{array}$ & $\begin{array}{l}\text { Lithium } 900 \text { mg/day } \\
\text { Haloperidol } 10 \text { mg/day } \\
\text { Biperiden hydrochloride } 4 \\
\text { mg/day }\end{array}$ \\
\hline 11 & $\begin{array}{l}\text { Olanzapine } 20 \text { mg/day } \\
\text { Lithium 1,500 mg/day } \\
\text { Clonazepam } 2 \text { mg/day }\end{array}$ & $\begin{array}{l}\text { Olanzapine } 15 \text { mg/day } \\
\text { Lithium 1,500 mg/day }\end{array}$ \\
\hline 12 & $\begin{array}{l}\text { Risperidone } 50 \mathrm{mg} / 2 \text { weeks } \\
\text { Haloperidol } 20 \mathrm{mg} / \text { day } \\
\text { Biperiden hydrochloride } 4 \\
\text { mg/day } \\
\text { Clonazepam } 2 \mathrm{mg} / \text { day }\end{array}$ & $\begin{array}{l}\text { Lithium } 600 \mathrm{mg} / \mathrm{day} \\
\text { Risperidone } 50 \mathrm{mg} / 2 \text { weeks }\end{array}$ \\
\hline
\end{tabular}


actin is used to normalize protein concentrations so that the observed changes reflect the changes occurring at a metabolic event. In urine samples however, the use of a housekeeping protein is not possible [16]. In here, an SDS-PAGE gel was run to visually assess the accuracy of protein concentrations (Fig. 1). The visual examination of the SDS-PAGE gel indicated that each sample displayed distinct bands without any evidence of smear and the measured protein concentrations were relatively well estimated in each urine sample and could be used for comparative proteome analysis (Fig. 1). In addition, the protein profiles of the control group (C) and remitted group
(R) samples were similar, while manic episode group (M) samples had a slightly different profile.

\section{Comparative 2-DE Analysis}

For comparative urine proteome analysis, well-resolved and reproducible 2-DE gels were produced and subjected to spot detection (Fig. 1). An average of 260 protein spots per analytical gel was detected. The overall mean coefficient for spot matching was $23 \%$ indicating that the protein distribution patterns among the gels were similar. Protein spots that significantly differed in expression (more than 2-fold) were selected and identified by MALDI-
A
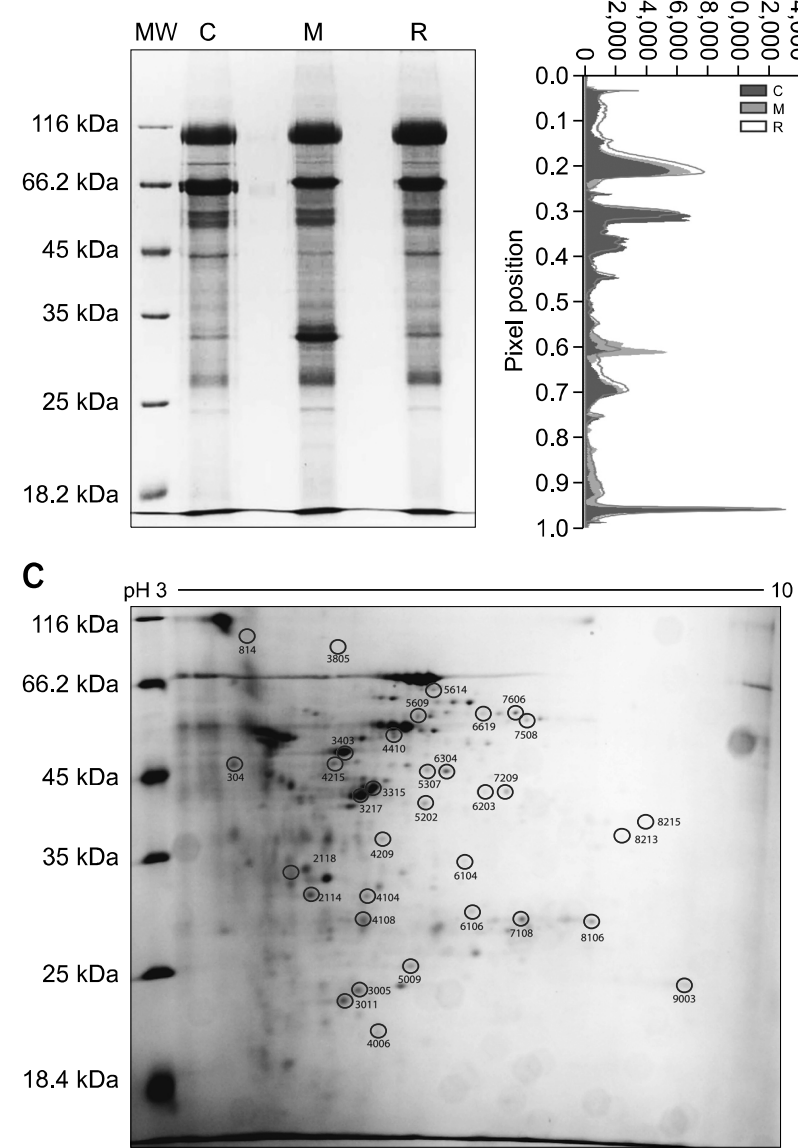

B
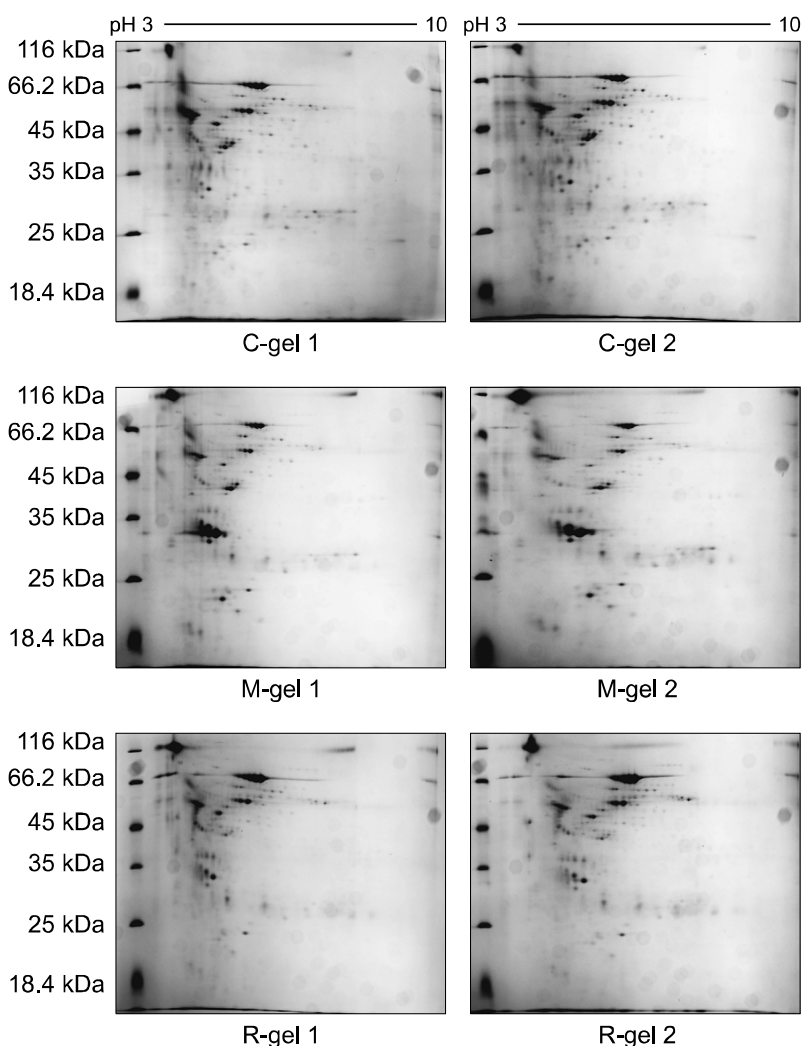

Fig. 1. (A) A representative SDS-PAGE image of urine proteins with corresponding histograms. Twenty $\mu$ g protein from each group was loaded to the gel, run at $180 \vee$ for 45 minutes before fixed and stained with colloidal Coomassie blue. (B) Representative two-dimensional gel electrophoresis (2-DE) images of the gels and identified protein spots. 2-DE electrophoresis was carried out with nonlinear $11 \mathrm{~cm}$ immobilized strips (pH $3-10$ ) for the first dimension separation and $12 \%$ SDS-PAGE gels for the second dimension separation. Staining of the gels were performed in Colloidal Coomassie Blue. (C) The spots labeled with standard spot numbers were excised and identified. Protein identification was performed by peptide mass finger printing via MASCOT (Matrix Science, Boston, MA, USA). Proteins of interest that displayed changes in their urine levels were $\alpha$-1-microglobulin and bukinin precursor (AMBP; SSP\#21189), Mannan-binding lectine serin protease-2 (MASP-2; SSP\#40069), alpha-1Bglycoprotein (SSP\#3805), prostaglandin-H2 D-isomerase (PGD2; SSP\#4108), Annexin A1 (SSP\#8213) and Ig gamma-1-chain (SSP\#8215). C, control group; $M$, manic episode group; $R$, remitted group. 
Table 3. List of the identified differentially regulated proteins and their respective MALDI-TOF/TOF data

\begin{tabular}{|c|c|c|c|c|c|c|c|c|}
\hline $\begin{array}{l}\text { Accession } \\
\text { number }\end{array}$ & Protein description & $\begin{array}{l}\text { Protein } \\
\text { mass (Da) }\end{array}$ & $\begin{array}{l}\text { Protein } \\
\text { score }\end{array}$ & $\begin{array}{c}\text { Calculated } \\
\mathrm{pl}\end{array}$ & $\begin{array}{l}\text { Expectation } \\
\text { score }\end{array}$ & Matches & $M / C$ & $\mathrm{R} / \mathrm{C}$ \\
\hline P02760 & $\begin{array}{c}\alpha-1 \text {-microglobulin and bukinin precursor } \mathrm{OS}= \\
\text { Homo sapiens, } \mathrm{GN}=\mathrm{AMBP}, \mathrm{PE}=1, \mathrm{SV}=1\end{array}$ & 38,974 & 193 & 5.95 & $1 \mathrm{E}-15$ & 22 & 5.47 & 0.15 \\
\hline P04217 & $\begin{array}{l}\text { Alpha-1B-glycoprotein OS }=\text { Homo sapiens, } \\
G N=A B G, P E=1, S V=3\end{array}$ & 54,239 & 131 & 5.58 & $5.6 \mathrm{E}-4$ & 16 & 118.34 & 113.2 \\
\hline O00187 & $\begin{array}{l}\text { Mannan-binding lectin serine protease- } 2 \mathrm{OS}= \\
\text { Homo sapiens, } \mathrm{GN}=\mathrm{MASP} 2, \mathrm{PE}=1, \mathrm{SV}=3\end{array}$ & 75,685 & 224 & 5.47 & 8.1E-19 & 16 & 19.45 & 3.21 \\
\hline P41222 & $\begin{array}{l}\text { Prostaglandin-H2 D-isomerase OS }= \\
\text { Homo sapiens, GN }=\text { PTGDS, } \mathrm{PE}=1, \mathrm{SV}=1\end{array}$ & 21,015 & 132 & 7.66 & $1.3 \mathrm{E}-09$ & 15 & 6.81 & 8.47 \\
\hline P04083 & $\begin{array}{l}\text { Annexin } \mathrm{A} 1 \mathrm{OS}=\text { Homo sapiens, } \mathrm{GN}= \\
\text { ANXA1, PE }=1, \mathrm{SV}=2\end{array}$ & 38,690 & 101 & 6.57 & $1.6 \mathrm{E}-6$ & 23 & 0.23 & 0.72 \\
\hline P01857 & $\begin{array}{l}\text { Ig gamma-1-chain C region } \mathrm{OS}= \\
\text { Homo sapiens, } \mathrm{GN}=\mathrm{IGHG} 1, \mathrm{PE}=1, \mathrm{SV}=1\end{array}$ & 36,083 & 86 & 8.46 & $4.8 \mathrm{E}-5$ & 14 & 21.15 & 3.12 \\
\hline
\end{tabular}

MALDI-TOF/TOF, Matriks assisted lazer desorption ionization time of flight; $\mathrm{pl}$, Isoelectric point; $\mathrm{M} / \mathrm{C}$, relative protein level ratio of Manic Episode group to Control group; R/C, relative protein level ratio of Remitted group to Control group.

Table 4. Comparisons of protein spot and band intensities among study groups

\begin{tabular}{|c|c|c|c|c|c|c|}
\hline \multirow{2}{*}{ Protein } & \multicolumn{3}{|c|}{ Mean $\pm \mathrm{SD}$} & \multicolumn{3}{|c|}{$p$ value } \\
\hline & Control (C) & Manic episode (M) & Remitted (R) & C-M & C-R & $M-R$ \\
\hline \multicolumn{7}{|l|}{ 2-DE spots } \\
\hline MASP-2 & $66,588.05 \pm 45,317.45$ & $1,295,148.20 \pm 106,726.20$ & $213,432.40 \pm 86,043.40$ & $<0.001$ & 0.059 & $<0.001$ \\
\hline AMBP & $1,102,368.15 \pm 71,240.75$ & $6,030,775.00 \pm 393,459.00$ & $168,183.65 \pm 51,368.25$ & $<0.001$ & $<0.001$ & 0.002 \\
\hline PGD2 & $231,111.25 \pm 203,049.45$ & $1,574,782.45 \pm 408,837.85$ & $1,957,044.85 \pm 533,961.95$ & 0.007 & 0.006 & 0.555 \\
\hline Alpha-1B-glycoprotein & $3,291.85 \pm 3,291.85$ & $389,548.30 \pm 76,034.70$ & $397,627.30 \pm 45,253.50$ & 0.001 & $<0.001$ & 0.919 \\
\hline Annexin A1 & $36,017.10 \pm 4,301.60$ & $8,112.25 \pm 4,695.85$ & $25,854.65 \pm 16,482.85$ & 0.002 & 0.360 & 0.284 \\
\hline Ig gamma-1-chain & $6,626.15 \pm 482.15$ & $140,155.00 \pm 36,140.00$ & $20,665.85 \pm 2,215.25$ & 0.03 & $<0.001$ & 0.033 \\
\hline \multicolumn{7}{|l|}{ WB results } \\
\hline MASP-2 & $249,848.25 \pm 26,611.79$ & $1,279,558.40 \pm 417,141.93$ & $52,867.35 \pm 51,200.74$ & 0.016 & $<0.001$ & 0.011 \\
\hline AMBP & $176,379.51 \pm 3,498.13$ & $717,753.29 \pm 173,567.76$ & $245,780.55 \pm 17,694.75$ & 0.006 & 0.018 & 0.036 \\
\hline
\end{tabular}

SD, standard deviation; 2-DE, two-dimensional gel electrophoresis; MASP-2, Mannan-binding lectine serin protease-2; AMBP, $\alpha-1$-microglobulin and bukinin precursor; PGD2, prostaglandin-H2 D-isomerase; WB, Western blot.

TOF/TOF analysis. A total of 34 differentially regulated protein spots were identified. The list of the identified proteins with their respective MALDI scores was presented in Table 3. Majority of the identified protein spots had originated from serum albumin (21 spots). There were other spots that belonged to $\alpha-1$-microglobulin and bukinin precursor (AMBP), uromodulin, alpha-1B-glycoprotein. Mannan-binding lectine serin protease-2 (MASP-2), prostaglandin-H2 D-isomerase (PGD2), Annexin A1 and Ig gamma-1-chain.

Comparisons of protein spot intensities among study groups were presented in Table 4 and Figure 2. AMBP, MASP-2, and Ig gamma-1-chain displayed significant increases in their abundance in the urine protein pool of the $M$ group in comparison to the $C$ and $R$ groups. On the other hand, alpha-1B-glycoprotein and PGD2 levels were significantly higher in the urine protein pool of the $M$ and $\mathrm{R}$ groups in comparison to the $\mathrm{C}$ group. Annexin A1 displayed a unique differential regulation pattern and was downregulated significantly in the urine protein pool of the $\mathrm{M}$ group in comparison to the $\mathrm{C}$ group.

\section{WB Analysis}

The protein pools from the $M, R$, and $C$ groups were subjected to WB analysis using antibodies against AMBP and MASP-2. Comparisons of WB analysis of AMBP and MASP-2 among study groups were demonstrated in Table 4 and Figure 3. The results for AMPB and MASP-2 verified the findings of the 2-DE experiments. AMBP and MASP-2 protein levels had significantly increased in the urine pools of $\mathrm{M}$ group in comparison to the urine pools of $\mathrm{C}$ and $\mathrm{R}$ groups. 


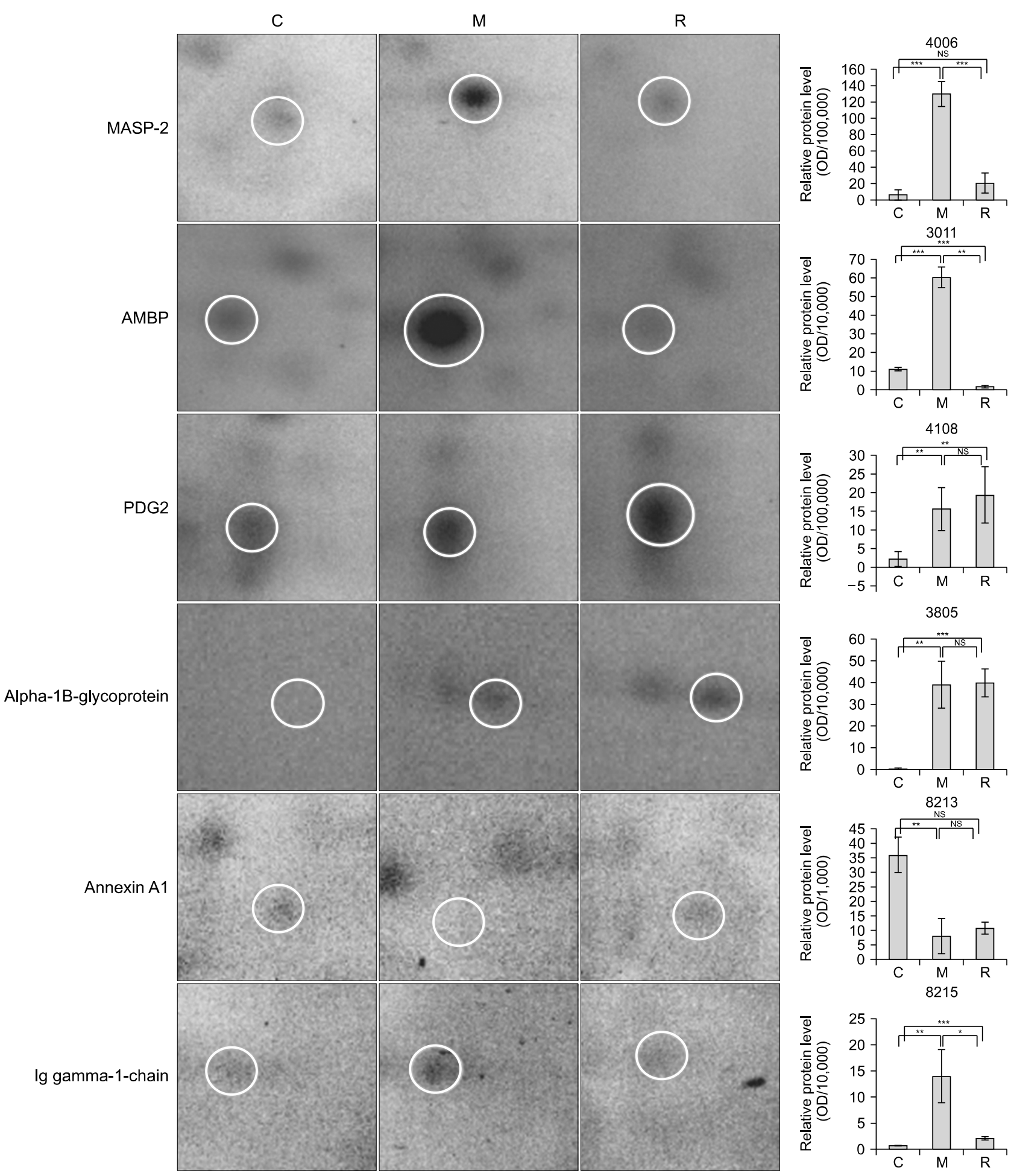

Fig. 2. Close-up images of the Mannan-binding lectine serin protease-2 (MASP-2), $\alpha-1$-microglobulin and bukinin precursor (AMBP), prostaglandin-H2 D-isomerase (PGD2), $\alpha$-1B-glycoprotein, Annexin A1 and Ig gamma-1-chain protein spots on the gels and the bar graphs (represented as mean \pm standard deviation) showing the measured corresponding spot intensities. The protein spots were labeled with circles. Relative quantification of the spot intensities was performed using PD Quest Advanced software (Bio-Rad, Hercules, CA, USA).

C, control group; $M$, manic episode group; $R$, remitted group; OD, optical density; NS, not significant.

An asterisk $\left(^{*}\right)$ represents a significant difference between the groups $\left({ }^{*} p<0.05 ;{ }^{* *} p<0.01,{ }^{* * *} p<0.001\right)$. 
A

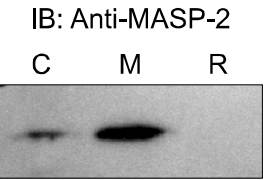

B

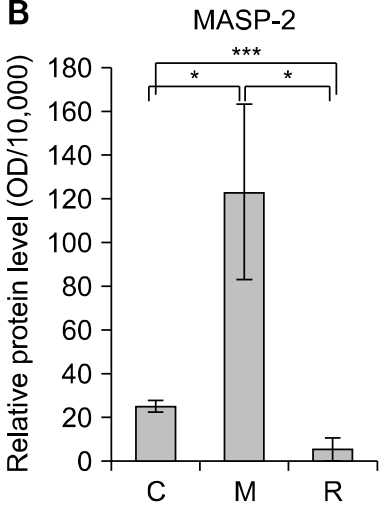

IB: Anti-AMBP
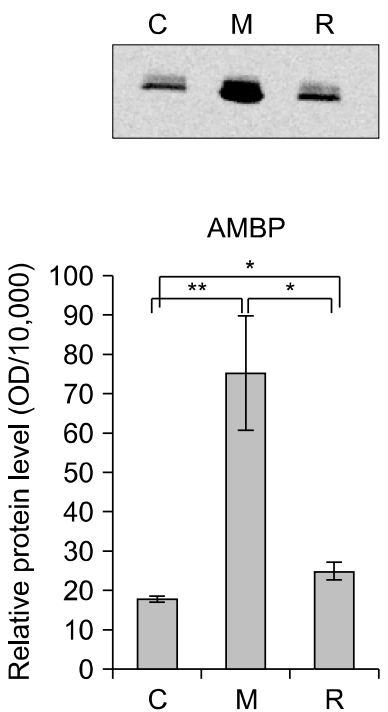

C
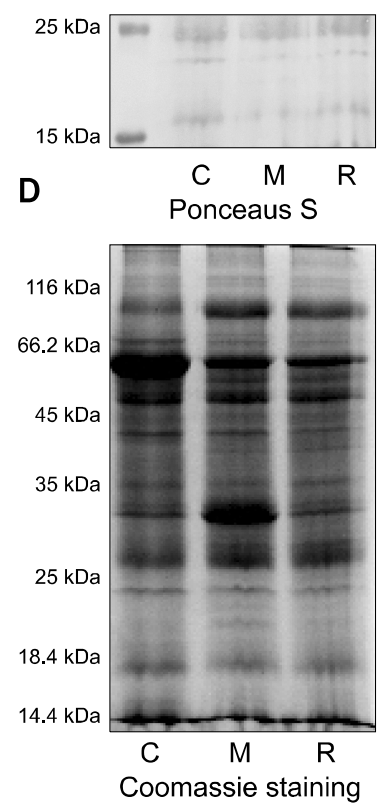

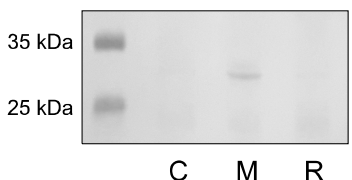

Ponceaus S

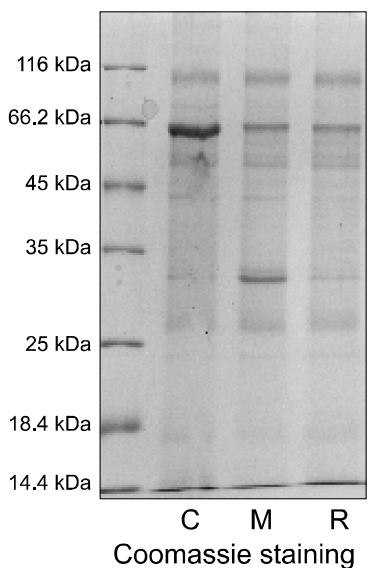

Fig. 3. (A) Representative Western blot images of Mannan-binding lectine serin protease-2 (MASP-2) and $\alpha-1$-microglobulin and bukinin precursor (AMBP) proteins. (B) The bar graphs for the band intensities belonging to MASP-2 and AMBP (Graph bars represent mean \pm standard deviation from three independent experiments). (C, D) Ponceau S and Coomassie Staining images of the membranes and gels, respectively, that were used in western blot analysis. Western blots for MASP-2 and AMBP were performed by loading $40 \mu \mathrm{g}$ and $4 \mu \mathrm{g}$ total protein per well and separating on $14 \%$ SDS-PAGE gels, respectively.

C, control group; $M$, manic episode group; $R$, remitted group.

An asterisk $\left({ }^{*}\right)$ represents a significant difference between the groups $\left({ }^{*} p<0.05{ }^{* *} p<0.01,{ }^{* * *} p<0.001\right)$.

\section{DISCUSSION}

$\mathrm{BD}$ is a common disorder affecting many people around the world. Despite such widespread occurrence, there is no reliable tool for the diagnosis of the disease [17-19]. Recent studies, on the other hand, using high technologies e.g., liquid chromatography coupled with tandem mass spectrometry (LC-MS/MS), Surface-enhanced laser desorption/ionization (SELDI), or MALDI were able to propose biomarker candidates for the diagnosis of $\mathrm{BD}$. For instance, Brain-derived neurotrophic factor (BNDF) was proposed to be a peripheral blood biomarker candidate for BD $[4,5]$. Similarly, interleukin- 6 and C-reactive protein (CRP) were suggested to be the serum-based biomarkers for $\mathrm{BD}[6,20]$. CRP levels are found to be $40-80 \%$ lower during depression episodes [6]. The use of high throughput multiplexed immunoassay technology compromised of 272 proteins demonstrated that growth/differentiation factor 15 (GDF-15), hemopexin (HPX), serine protease hepsin (HPN), matrix metalloproteinase-7 (MMP-7), retinol binding protein 4 (RBP-4) and transthyretin (TTR) proteins possess the power to be evaluated as biomarker proteins for BD [21].

In addition to blood-based protein markers, tissuebased biomarker proteins were also searched especially for understanding the pathophysiology of the disease. Analysis of protein levels in 89 postmortem frontal cortices with depressive disorders including BD revealed that Glial fibrillary acidic protein (GFAP), dihydropyrolidinerelated protein 2 and ubiquinone cyt-C oxidoreductase core protein possesses potentials as biomarker candidates [8]. As of 2020, there is no urine-based proteomics study performed in $\mathrm{BD}$, although metabolomics studies evaluated the potential use of urine as a biomarker source $[22,23]$.

Main findings of this study was summarized in Table 5. AMBP, MASP-2 and Ig gamma-1-chain levels were increased while Annexin A1 level was decreased in the urine protein pools of patients with manic episode compared to these patients when remitted and control subjects. PGD2 and alpha-1B-glycoprotein were increased in the urine protein pool of BD patients both in manic and re- 
Table 5. Main findings of the study

\begin{tabular}{lll}
\hline \multicolumn{1}{c}{ Increases in manic episode } & Decreases in manic episode & Increases in bipolar disorder \\
\hline AMBP (both in 2-DE and WB analysis) & Annexin A1 (2-DE analysis) & PGD2 (2-DE analysis) \\
$\begin{array}{l}\text { MASP-2 (both in 2-DE and WB analysis) } \\
\text { Ig gamma-1-chain (2-DE analysis) }\end{array}$ & Alpha-1B-glycoprotein (2-DE analysis) \\
\hline
\end{tabular}

AMBP, $\alpha$-1-microglobulin and bukinin precursor; MASP-2, Mannan-binding lectine serin protease-2; PGD2, prostaglandin-H2 D-isomerase; 2-DE, two-dimensional gel electrophoresis; WB, Western blot.

mission phases compared to control subjects.

The differentially regulated proteins were subjected to bioinformatics analysis using the STRING database to elucidate functional relevance with biological pathways [24]. MASP-2 exclusively helps activation of the complement system [25]. After activation by auto-catalytic cleavage, MASP-2 cleaves C2 and C4 to the formation of C3 convertase. In general, the presence of immune response activating proteins in urinary tract is due to a response to microbial assault. However, there are serum-based studies in the literature reporting associations between MASP-2 and several psychological disorders [26-28]. In a study, Mannose-binding leptin (MBL)-bound MASP-2 activity and complement activation capacity was found to be increased in sera of patients with schizophrenia compared to controls [27]. Researchers have hypothesized that the high activity of MBL-MASP-2 interaction causes low level chronic inflammatory processes, increased permeability of the blood-brain barrier (BBB) and excessive production of anti-brain autoantibodies which eventually cause tissue damage. In another study, performed with bipolar and panic disorder patients, lower MASP-2 serum concentrations in both disorders are detected although the decrease is more evident in panic disorder [26]. In our study, we demonstrated that in the pooled urine samples, at least 5-fold increase was observed in MASP-2 levels during manic episode and this level has significantly decreased after remission indicating that MASP-2 could be a strong biomarker candidate for manic episode. In our opinion, the MASP-2 protein appears to be at the center of the dysregulated physiological events occurring in BD patients during manic episode.

The other protein that displayed changes in its levels in the urine pools of $\mathrm{BD}$ patients during manic episode was AMBP. AMBP is an interesting multifunctional serum protein and can be cleaved into 2 functionally distinct proteins, namely $\alpha-1$-microglobulin and bukinin. The AMBP protein spot that we cut and identified from 2-DE gels esti- mated to have an approximate molecular weight of 33 $\mathrm{kDa}$ indicating that it may belong to $\alpha-1$-microglobulin rather than Bukinin domain of AMBP. To further verify our prediction, we analyzed the raw data gathered from MALDI-TOF/TOF spectrum. Our analysis verified the fact that the peptides captured by the MALDI-TOF/TOF belonged to $\alpha-1$-microglobulin domain of AMBP. In addition, a monoclonal antibody against $\alpha$-1-microglobulin further verified our findings in western blots generated from urine pools. At least 4-fold increase was observed in $\alpha-1$-microglobulin levels during manic episode compared to the controls and this level has significantly decreased after remission. $\alpha-1$-microglobulin appears to be a biomarker candidate for manic episode according to the results of this study. In a study, the $3222.17 \mathrm{~m} / \mathrm{z}$ peptide originating from $\alpha-1$-microglobulin domain of AMBP is found to be differentially regulated in patients with major depression. Researchers have commented that AMBP participates in the regulation of immune and oxidation systems [29]. In this sense, our study is the second study which detected regulation in $\alpha-1$-microglobulin levels in the urine samples associated with a psychiatric disorder. $\alpha-1$-microglobulin binds and degrades free radicals and oxidizing agents, therefore the high AMBP protein levels indicate the damaging effects of free radicals, which can cause lipid and protein oxidation and cell death [30]. Its main function is that of a potent free heme binder and as an antioxidant protein [31].

There were other differentially regulated proteins which were not verified by western blotting despite the changes observed in 2-DE gels. Those proteins were, namely, PGD2, $\alpha-1 \mathrm{~B}$ glycoprotein, Annexin A1 and IgG-1 chain.

Prostoglandin synthesis plays a pivotal role in metabolic homeostasis, sleep regulation, adipogenesis, allergic response and inflammation. PGD-synthase functions as both a neuromodulator and a trophic factor in the central nervous system [32]. It is worth to mention that serum and tissue-based gene expression studies revealed that dis- 
turbances in the arachidonic acid cascade and prostaglandin pathway have been proposed as a pathophysiological mechanism in the regulation of mood and suggested to contribute to the underlying biological background for BD [33,34]. In our study, PGD2 displayed increases in its levels in urine samples of patients with manic episode in comparison to the controls. After remission, PGD2 levels kept increasing indicating that PGD2 may be associated with the $\mathrm{BD}$ itself rather than the manic episode.

Alpha-1B-glycoprotein is a secreted plasma protein and a member of the immunoglobulin superfamily with a reasonable role in the immune system and in cell adhesion. Bellei et al. [35] revealed increased alpha-1B-glycoprotein by proteomic analysis of plasma samples of patients with restless leg syndrome. Biswas et al. [36] have identified, by an immunoproteomic approach, a higher expression of alpha-1B-glycoprotein in synovial fluid of patients with rheumatoid arthritis, proposing this glycoprotein as a biomarker of diagnostic importance for rheumatoid arthritis. Ditzen et al. [37] revealed 11 dysregulated proteins in cerebrospinal fluid of patients with major depression including alpha-1B-glycoprotein. Evidence on alpha-1B-glycoprotein in pathophysiology of psychiatric disorders is limited. Our finding of increased alpha-1Bglycoprotein in urine samples of the patients compared to controls may support the hypothesis of the increased inflammatory response in $\mathrm{BD}$.

Glucocorticoids mediate their multiple anti-inflammatory effects through many effector molecules. Annexin A1 is one of such effector molecule [38]. Annexin A1 and glucocorticoids as effectors of the resolution of inflammation. Annexin A1 is a protein with multifunctional roles in innate and adaptive immunity mainly devoted to the regulation of inflammatory cells and the resolution of inflammation. Annexin A1 may play an anti-inflammatory effect in the context of innate immunity by inhibiting transmigration of neutrophils towards an inflammatory site. Glucocorticoids play their anti-inflammatory effects prevalently at this step by regulating transmigration of neutrophils mediated by Annexin A1 [39]. It plays a role in glucocorticoid-mediated down-regulation of the early phase of the inflammatory response and promotes resolution of inflammation and wound healing. Annexin A1containing extracellular vesicles and polymeric nanoparticles promote epithelial wound repair [40]. Yet our knowledge about the role and effects of Annexin A1 in brain diseases is very limited. A recent study revealed that Annexin A1 may be a neuroprotective determinant for BBB integrity [41]. We could not find a study investigating Annexin A1 in psychiatric disorders. In our study, the decrease of Annexin A1 in manic episode compared to controls reveals that manic episode is somehow a state of pro-inflammatory domination whereas anti-inflammatory processes are supressed. There was no significant difference with controls when patients are remitted. The decrease in Annexin A1 may led to a failure in BBB integrity, causing flee of inflammatory proteins to central nervous system. Patel et al. [42] proposed a model wherein transient or persistent disruption of BBB integrity is associated with decreased central nervous system protection and increased permeability of pro-inflammatory (e.g., cytokines, reactive oxygen species) substances from the peripheral blood into the brain. They suggested that the disruption in the BBB may be the missing link between brain and body inflammation in BD.

Human Ig gamma-1 binds to every type of human Fc receptor found on immune cells, leading to a variety of events including pro-inflammatory cytokine production, phagocytosis and complement activation, depending on the receptor or protein bound, the cell type with which the receptor is associated and other immune factors present locally [43]. Human IgG-1 binds complement factor $\mathrm{C} 1 \mathrm{q}$ and is capable of activating the complement cascade via the classic route as well as the alternative route. Similar to the biological effects of MASP-2, IgG-1 promotes the inflammatory processes [44].

In conclusion, using 2-DE coupled to MALDI-TOF/TOF approach, several differentially expressed proteins were identified in the urine samples from BD patients in comparison to the healthy controls. Two proteins; MASP-2 and $\mathrm{AMBP}$ discriminated manic episode from remission period and healthy controls both in 2-DE gels and WB analysis. Although other differentially regulated proteins, namely, PGD2, $\alpha-1$ B glycoprotein, Annexin A1 and IgG-1 chain levels were not assessed with the western blotting, the decrease in Annexin A1 and increase in IgG-1 chain levels appeared to be related with "Manic Episode" while the increase in PGD2 and $\alpha-1 B$ glycoprotein levels appeared to be related with "Bipolar Disorder" according to the 2-DE results. Regarding the known biologic effects of these proteins, we may comment that our results mainly indicate the pro-inflammatory roots of BD. Proteomic 
based clinical studies are a few in psychiatry. Considering the limitations of this study, proteomic based prospective clinical studies in large samples including all mood states are needed. Comparing BP patients with other psychiatric disorders as well as other medical conditions should be beneficial in terms of the specificity of the findings. Further evaluations on the effects of medication and other confounding factors are necessary.

The small sample size was the main limitation of this study. Also we were unable to collect samples from drug-naive BD patients. Therefore, the influence of medications on proteom profiles has not been evaluated. Most patients were under the antipsychotic and mood stabilizer medication when admitted to hospital and different medications may induce different protein expression [45]. Using pooled urine samples may be another limitation of this study comparing to individual by individual assessments. We matched the patients and controls just for age and sex where some other parameters like body mass index or daily physical activity may influence the measured variables. We did not have the chance to evaluate the proteomic changes in depressive episode which should provide an integrative viewpoint. Lack of comparison with other psychiatric disorders as well as other neuropsychiatric conditions was also another limitation of this study on the specifity of findings to $\mathrm{BD}$. As we know this is the first study of urine-based proteomics comparing BD patients to controls and further comparing manic and remission phases of the disease. The well established 2-DE coupled to MALDI-TOF/TOF MS methodology is the other strength of this study.

\section{Acknowledgments}

This research is supported by Kocaeli University Scientific Research Projects Unit (KOU-BAP/2018-002).

\section{- Conflicts of Interest}

No potential conflict of interest relevant to this article was reported.

\section{Author Contributions}

Conceptualization: Cem Cerit. Investigation: Mehmet Sarıhan, Ömer Nart and Hilmi Yaşar. Data curation: Mehmet Sarıhan. Data acquisition: Ömer Nart and Hilmi Yaşar. Supervision: Murat Kasap and Gürler Akpınar. Writing-original draft: Cem Cerit and Murat Kasap.
Writing - review \& editing: Gürler Akpınar.

\section{ORCID}

Cem Cerit

Mehmet Sarıhan

Ömer Nart

Murat Kasap

Hilmi Yaşar

Gürler Akpınar https://orcid.org/0000-0002-0189-7003

https://orcid.org/0000-0002-1565-5718

https://orcid.org/0000-0002-3192-130X

https://orcid.org/0000-0001-8527-2096

https://orcid.org/0000-0002-5395-8103

https://orcid.org/0000-0002-9675-3714

\section{REFERENCES}

1. Kupfer DJ. The increasing medical burden in bipolar disorder. JAMA 2005;293:2528-2530.

2. Teixeira AL, Salem H, Frey BN, Barbosa IG, Machado-Vieira R. Update on bipolar disorder biomarker candidates. Expert Rev Mol Diagn 2016;16:1209-1220.

3. Bartoli F, Carrà G, Clerici M. Update on bipolar disorder biomarker candidates: what about uric acid/adenosine hypothesis? Expert Rev Mol Diagn 2017;17:105-106.

4. de Oliveira GS, Ceresér KM, Fernandes BS, Kauer-Sant'Anna M, Fries GR, Stertz L, et al. Decreased brain-derived neurotrophic factor in medicated and drug-free bipolar patients. J Psychiatr Res 2009;43:1171-1174.

5. Grande I, Fries GR, Kunz M, Kapczinski F. The role of BDNF as a mediator of neuroplasticity in bipolar disorder. Psychiatry Investig 2010;7:243-250.

6. Jacoby AS, Munkholm K, Vinberg M, Pedersen BK, Kessing LV. Cytokines, brain-derived neurotrophic factor and C-reactive protein in bipolar I disorder - Results from a prospective study. J Affect Disord 2016;197:167-174.

7. Rolstad S, Jakobsson J, Sellgren C, Isgren A, Ekman CJ, Bjerke $\mathrm{M}$, et al. CSF neuroinflammatory biomarkers in bipolar disorder are associated with cognitive impairment. Eur Neuropsychopharmacol 2015;25:1091-1098.

8. Johnston-Wilson NL, Sims CD, Hofmann JP, Anderson L, Shore AD, Torrey EF, et al. Disease-specific alterations in frontal cortex brain proteins in schizophrenia, bipolar disorder, and major depressive disorder. The Stanley Neuropathology Consortium. Mol Psychiatry 2000;5:142-149.

9. Maffioletti E, Tardito D, Gennarelli M, Bocchio-Chiavetto L. Micro spies from the brain to the periphery: new clues from studies on microRNAs in neuropsychiatric disorders. Front Cell Neurosci 2014;8:75.

10. Monfrim X, Gazal M, De Leon PB, Quevedo L, Souza LD, Jansen $\mathrm{K}$, et al. Immune dysfunction in bipolar disorder and suicide risk: is there an association between peripheral corticotropin-releasing hormone and interleukin-1 $\beta$ ? Bipolar Disord 2014;16:741-747.

11. Sandberg JV, Jakobsson J, Pålsson E, Landén M, Mathé AA. Low neuropeptide $Y$ in cerebrospinal fluid in bipolar patients is associated with previous and prospective suicide attempts. Eur Neuropsychopharmacol 2014;24:1907-1915. 
12. An M, Gao Y. Urinary biomarkers of brain diseases. Genomics Proteomics Bioinformatics 2015;13:345-354.

13. Chengappa KN, Baker RW, Shao L, Yatham LN, Tohen M, Gershon $\mathrm{S}$, et al. Rates of response, euthymia and remission in two placebo-controlled olanzapine trials for bipolar mania. Bipolar Disord 2003;5:1-5.

14. Pieper R. Preparation of urine samples for proteomic analysis. Methods Mol Biol 2008;425:89-99.

15. Kanli A, Kasap M, Yoneten KK, Akpinar G, Gulkac MD. Identification of differentially regulated deceitful proteins in SH-SY5Y cells engineered with Tet-regulated protein expression system. J Cell Biochem 2018;119:6065-6071.

16. Butler TAJ, Paul JW, Chan EC, Smith R, Tolosa JM. Misleading westerns: common quantification mistakes in Western blot densitometry and proposed corrective measures. Biomed Res Int 2019;2019:5214821.

17. Bayes A, Parker G, Paris J. Differential diagnosis of bipolar II disorder and borderline personality disorder. Curr Psychiatry Rep 2019;21:125.

18. McIntyre RS, Zimmerman M, Goldberg JF, First MB. Differential diagnosis of major depressive disorder versus bipolar disorder: current status and best clinical practices. J Clin Psychiatry 2019; 80:ot18043ah2.

19. Menezes IC, von Werne Baes C, Lacchini R, Juruena MF. Genetic biomarkers for differential diagnosis of major depressive disorder and bipolar disorder: a systematic and critical review. Behav Brain Res 2019;357-358:29-38.

20. Munkholm K, Vinberg M, Vedel Kessing L. Cytokines in bipolar disorder: a systematic review and meta-analysis. J Affect Disord 2013;144:16-27.

21. Frye MA, Nassan $M$, Jenkins GD, Kung $S$, Veldic $M$, Palmer $\mathrm{BA}$, et al. Feasibility of investigating differential proteomic expression in depression: implications for biomarker development in mood disorders. Transl Psychiatry 2015;5:e689.

22. Yoshimi N, Futamura T, Bergen SE, Iwayama Y, Ishima T, Sellgren C, et al. Cerebrospinal fluid metabolomics identifies a key role of isocitrate dehydrogenase in bipolar disorder: evidence in support of mitochondrial dysfunction hypothesis. Mol Psychiatry 2016;21:1504-1510.

23. Zhang R, Zhang T, Ali AM, Al Washih M, Pickard B, Watson DG. Metabolomic profiling of post-mortem brain reveals changes in amino acid and g/ucose metabolism in mental illness compared with controls. Comput Struct Biotechnol J 2016;14:106-116.

24. Szklarczyk D, Gable AL, Lyon D, Junge A, Wyder S, HuertaCepas J, et al. STRING v11: protein-protein association networks with increased coverage, supporting functional discovery in genome-wide experimental datasets. Nucleic Acids Res 2019;47:D607-D613.

25. Kidmose RT, Laursen NS, Dobó J, Kjaer TR, Sirotkina $S$, Yatime $\mathrm{L}$, et al. Structural basis for activation of the complement system by component C4 cleavage. Proc Natl Acad SCi U S A 2012;109:15425-15430.
26. Foldager L, Köhler O, Steffensen R, Thiel S, Kristensen AS, Jensenius JC, et al. Bipolar and panic disorders may be associated with hereditary defects in the innate immune system. J Affect Disord 2014;164:148-154.

27. Foldager L, Steffensen R, Thiel S, Als TD, Nielsen HJ, Nordentoft $\mathrm{M}$, et al. MBL and MASP-2 concentrations in serum and MBL2 promoter polymorphisms are associated to schizophrenia. Acta Neuropsychiatr 2012;24:199-207.

28. Woo JJ, Pouget JG, Zai CC, Kennedy JL. The complement system in schizophrenia: where are we now and what's next? Mol Psychiatry 2020;25:114-130

29. Wang Y, Chen J, Chen L, Zheng P, Xu HB, Lu J, et al. Urinary peptidomics identifies potential biomarkers for major depressive disorder. Psychiatry Res 2014;217:25-33.

30. Gertow J, Ng CZ, Mamede Branca RM, Werngren O, Du L, Kjellqvist $\mathrm{S}$, et al. Altered protein composition of subcutaneous adipose tissue in chronic kidney disease. Kidney Int Rep 2017;2:1208-1218.

31. Zager RA. Alpha 1 microglobulin: a potentially paradoxical anti-oxidant agent. Adv Tech Biol Med 2017;5:238.

32. Marín-Méndez JJ, Patiño-García A, Segura V, Ortuño F, Gálvez MD, Soutullo CA. Differential expression of prostaglandin D2 synthase (PTGDS) in patients with attention deficit-hyperactivity disorder and bipolar disorder. I Affect Disord 2012; 138:479-484.

33. Duncan RE, Bazinet RP. Brain arachidonic acid uptake and turnover: implications for signaling and bipolar disorder. Curr Opin Clin Nutr Metab Care 2010;13:130-138.

34. Gurvich A, Begemann M, Dahm L, Sargin D, Miskowiak K, Ehrenreich $\mathrm{H}$. A role for prostaglandins in rapid cycling suggested by episode-specific gene expression shifts in peripheral blood mononuclear cells: a preliminary report. Bipolar Disord 2014;16:881-888.

35. Bellei E, Monari E, Ozben S, Koseoglu Bitnel M, Topaloglu Tuac S, Tomasi A, et al. Discovery of restless legs syndrome plasmatic biomarkers by proteomic analysis. Brain Behav 2018;8:e01062.

36. Biswas S, Sharma S, Saroha A, Bhakuni DS, Malhotra R, Zahur $\mathrm{M}$, et al. Identification of novel autoantigen in the synovial fluid of rheumatoid arthritis patients using an immunoproteomics approach. PLoS One 2013;8:e56246.

37. Ditzen C, Tang N, Jastorff AM, Teplytska L, Yassouridis A, Maccarrone G, et al. Cerebrospinal fluid biomarkers for major depression confirm relevance of associated pathophysiology. Neuropsychopharmacology 2012;37:1013-1025.

38. Perretti M, D'Acquisto F. Annexin A1 and g/ucocorticoids as effectors of the resolution of inflammation. Nat Rev Immunol 2009:9:62-70.

39. Bruschi M, Petretto A, Vaglio A, Santucci L, Candiano G, Ghiggeri GM. Annexin A1 and autoimmunity: from basic science to clinical applications. Int J Mol Sci 2018;19:1348.

40. Leoni G, Neumann PA, Kamaly N, Quiros M, Nishio H, Jones $\mathrm{HR}$, et al. Annexin A1-containing extracellular vesicles and 
polymeric nanoparticles promote epithelial wound repair. J Clin Invest 2015;125:1215-1227.

41. Gussenhoven R, Klein L, Ophelders DRMG, Habets DHJ, Giebel B, Kramer BW, et al. Annexin A1 as neuroprotective determinant for blood-brain barrier integrity in neonatal hypoxic-ischemic encephalopathy. J Clin Med 2019;8:137.

42. Patel JP, Frey BN. Disruption in the blood-brain barrier: the missing link between brain and body inflammation in bipolar disorder? Neural Plast 2015;2015:708306.

43. Beck A, Carter PJ, Gerber HP, Lugovskoy AA, Wurch T, Junutula
JR, et al. 8th Annual european antibody congress 2012- Nov 27-28, 2012, Geneva, Switzerland. MAbs 2013;5:339-357.

44. Moore GL, Chen H, Karki S, Lazar GA. Engineered FC variant antibodies with enhanced ability to recruit complement and mediate effector functions. MAbs 2010;2:181-189.

45. Berk $M$, Conus $P$, Kapczinski $F$, Andreazza AC, Yücel $M$, Wood SJ, et al. From neuroprogression to neuroprotection: implications for clinical care. Med J Aust 2010;193(S4):S36S4O. 